$\xi=1$ 国

\title{
Developing WebQuest 2.0 model for promoting computational thinking skill
}

\author{
Le Diem Bui ${ }^{1 *}$, Yong Gi Kim², Won $\mathrm{Ho}^{3}$, Ho Thi Thu $\mathrm{Ho}^{4}$, Nguyen Khang Pham ${ }^{5}$ \\ ${ }^{1,2}$, AI Lab, Computer Science Department, Gyeongsang National University, Korea \\ ${ }^{3}$ Electrical Engineering Department, Kongju National University, Korea \\ ${ }^{4,5}$ Can Tho University, Viet Nam \\ *Corresponding authorE-mail: bldiem@ctu.edu.vn
}

\begin{abstract}
In this paper, we propose a new WebQuest model using Web 2.0 services to organize online learning activities by using OKMindmap for building WebQuest and suggest Scratch projects created by students for outcome. WebQuest is an inquiry-oriented lesson format in which most or all the information that learners work with comes from the web. WebQuests can be a valuable addition to a collaborative classroom. One of the goals is to increase critical thinking by employing higher levels of Bloom's Taxonomy and Webb's Depth of Knowledge. WebQuests can be a versatile tool for teaching students. OKMindmap is a useful, free, easy to use knowledge manipulation tool for content creation and management. It helps building an innovative collaborating environment for online class and provides a way to embed web service as a node. With this capability, any web service can be embedded as a node on a single map. Moreover, many users (about 40) can work on a same map together. Scratch is a free educational programming language that was developed by the Lifelong Kindergarten Group at the Massachusetts Institute of Technology (MIT) with over 21 million registered users and 25 million shared projects. Scratch is designed to be fun, educational, and easy to learn. It's a programming language for all with the tools for creating interactive stories, games, art, simulations, and more, using block-based programming. Facebook is also used as a tool for connecting and sharing WebQuest with students. This model was experimented at the School of Education at Can Tho University, which brought us positive results through blended learning. Our desire is to build a WebQuest library in a simple, cost-effective way through this STEM-style education so that inservice and preservice teachers can share together for the best professional development during the current industrial revolution 4.0 .
\end{abstract}

Keywords: WebQuest; OKMindmap; Scratch; Facebook; STEM

\section{Introduction}

A WebQuest is one method of how teachers can integrate technology into classrooms, which is a growing area of interest as information technology creates new learning opportunities and becomes more accessible across the world [4-5]. WebQuests are appealing because they provide structure and guidance both for students and for teachers. The stated ideal of engaging higherlevel thinking skills though making good use of limited computer access seems to resonate with many educators. According to Dodge Bernie, five rules for writing a great WebQuest are: (1) Find great sites. (2) Orchestrate your learners and resources. (3) Challenge your learners to think. (4) Use the medium and (5) Scaffold high expectations [6].

For bringing ICT the most effectively to schools, we believe that the ICT tools should be simple and easy to use and Web 2.0 is the best choice in this case. Bernie Dodge described that WebQuests and Web 2.0 go together like chocolate and peanut butter and from then on, the definition of WebQuest 2.0 was be used by some researchers. WebQuest 2.0 in OKMindmap style is a new model suggested in this paper. This model use OKMindmap web 2.0 service as a platform for creating WebQuest and the task of WebQuest should be contained programming activities with Scratch programming language to promote computational thinking to teachers and students. In order to do this research, we temporally set up a server with domain name is http://webquest.ctu.edu.vn/ in which users can access to create mindmap, WebQuest and get support to learn programming with Scratch at https://scratch.mit.edu/. For evaluation phase of this WebQuest model, we ask students to use http://www.drscratch.org/ for self assessing computational thinking (CT) skills through their Scratch projects automatically. Thanks to comments and suggestions of Dr. Scratch tool, students can upgrade their programs gradually for higher score to improve their CT skills better and better.

Especially, the online tools used in this research are very simple, easy to use and totally free, and in the case of without Internet, there is alternative way by using offline tools. Users can work with these webpages in several languages, including Vietnamese. The libraries of WebQuest created by teachers in OKmindmap style and Scratch projects created by students are the open educational resources (OER) that can be shared and accessed by everyone through Internet using computers or smartphones. With this OER model, STEM education can become wider easily in cost effective way. "Bringing CT to STEM Education"[4] with Scratch of MIT is the first step to help developing skilled labour in the Mekong Delta to be more dynamic and adaptable to the ever changing economy and employment market because CT was proved that is the 21 st century skill [5]. 
To conduct this research, we put the two following research questions: (1) How to apply this WebQuest model in STEM higher education in Mekong Delta? (2) How to evaluate the effect of this model?

This paper follows by the second sections mentioned about a new WebQuest model in stem education with OKMindmap as platform and Scratch projects created by students as outcome of WebQuest, the third section is the methodology to conduct the research, then the fourth section is about resutls and discussion about our suggested model. Finally is our conclusion.

\section{New Webquest 2.0 Model In Stem Educa- tion}

\subsection{WebQuest in OKMindmap Style:}

OKMindmap is a Web-Based open Mindmap service of Jinotech company in South Korea. It can be used to build an innovative collaborating environment by using embedding node capacity[7]. OKMindmap interface comprises three languages English, Korean and Vietnamese. Recently, OKMindmap has been updated several new features that may make it the best tool for content creation and management for knowledge manipulation. With OKMindmap service, users can insert image, video, hyperlink and especially connect with Moodle Learning Management System through LTI connection function. Besides that, OKMindmap is very flexible in sharing function. Users can create a branch map and share it to others user to edit together. This function help create a working group easily and effectively while 40 users (students in a class) can access to a map for collaboratively brainstorming about their lesson. Each map created by OKMindmap tool has an URL address in long and short form (bit.ly form) that can be share easily. With SNS integration, user can share their map to Facebook, G+ and Twitter by the icons within it.

In order to use OKMindmap web service, users need to sign up an account and use it to manage mind maps created in anytime and anywhere with Internet connection. Vietnamese interface added recently help Vietnamese can access it conveniently. In the case of having no Internet Access, users can export/import it with Freemind (a free mind mapping software) file style and use it offline. Moreover, OKMindmap webpage can be exported to several kinds of file such as xml,ppt, svg, png, html and text. With group management function, user can work and share work in group easily. While working with OKMindmap, user can also talk to each other using Chatting function. This makes collaboration and communication to create mindmap more and more effectively. The webpage edit function help to insert and modify a webpage where users can find the functions to insert formulas and special characters.

WebQuests [8] give students the opportunity to engage in authentic problem solving tasks while developing skills in group work, ICT, information and critical literacy. The WebQuest structure can be applied to any topic or cross-curricular theme, and is especially suitable for complex issues where there are several variables and viewpoints to consider. WebQuests engage students in 21 st century learning that promotes critical thinking and problem solving while deepening their understanding of STEM concepts. Authentic tasks and place-based learning provides a rich context for applying knowledge. At the same time, it should be noted that technology alone does not guarantee solutions to educational problems. It will only have a positive impact when used within the framework of a solid strategic plan for supporting learning and teaching [9]. Actually, WebQuest can be designed in several types such as Google Site, Google Docs, in some WebQuest template as Zunal, Quesgarden,... but in this research, we do suggest to design WebQuest in OKMindmap style because of the simple and flexible functions of OKMindmap service as mentioned above help users easily to create good WebQuest. By working with WebQuest in OKmindmap style, users can be more creative, easily collaborative, and time-saving and it is the important characteristics of this suggested model, as be seen in Figure 1 at the link http://bit.ly/2jH9KT2.

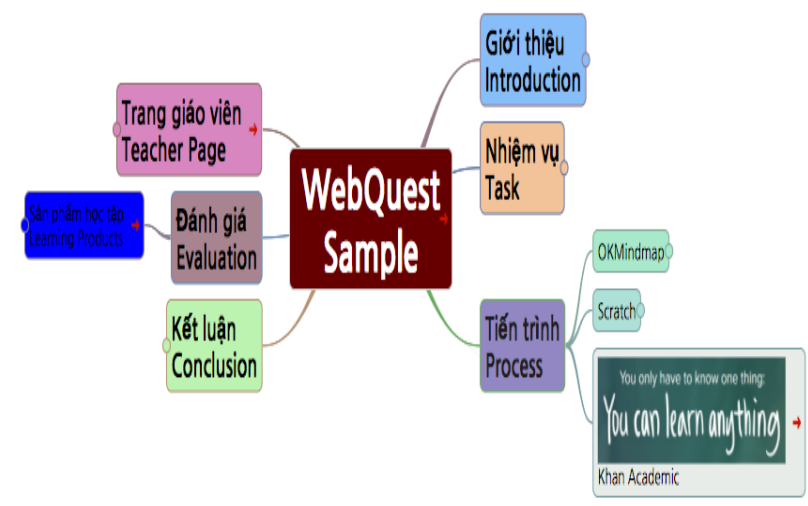

Fig 1: The Sample of WebQuest in OKMindmap style

\subsection{Scratch projects as WebQuest outcome}

Mitchel Resnick (who leads the Lifelong Kindergarten Research Group at the MIT Media Lab) declared that: "For us, coding is not a set of technical skills but a new type of literacy and personal expression, valuable for everyone, much like learning to write. We see coding as a new way for people to organize, express, and share their ideas." and he wrote, in 2009, the paper about "[10] Scratch: Programming for all".

Since the release of Scratch in 2007, young people around the world have programmed and shared more than 15 million Scratch projects - with more than 22,000 new projects being shared in the online community every day. The first generation of Scratch was an application that kids downloaded to local machines. With Scratch 2.0, the second and current generation of Scratch, kids create and share their interactive stories, games, and animations directly in web browsers. Now, the MIT Scratch Team is preparing to support that creativity in new ways, with a project informally called Scratch 3.0 - the next generation of Scratch that will be released soon in next year.

According to Jeanette Wing [11-12]: "Computational thinking is a fundamental skill for everyone, not just for computer scientists. To reading, writing, and arithmetic, we should add computational thinking to every child's analytical ability." And Carnegie Mellon Center for Computational Thinking announced that "The impact of computing extends far beyond science, however, affecting all aspects of our lives. To flourish in today's world, everyone needs computational thinking".

Actually, CT means "Solving problems", "Applying abstraction and decomposition", "Thinking algorithmically - what's the process?" "Thinking conceptually - what's the model?", "Understanding how things repeat and scale", "Dealing with errors",... CT is not thinking like a computer, nor even thinking about computation but thinking with the same clarity and strategy that is required to command machines even if you are not commanding a machine. And that are all about the reason why Scratch should be used to promote CT. In this research, Scratch projects are chosen to be outcome of WebQuest assignment in order to "challenge the learners to think" and "scaffold high expectations" in CT - "a digital age skill for everyone".

\section{Methodology}

\subsection{Theoretical research method}

Methods of theoretical research [14-15] were applied to study the theoretical backgrounds of WebQuest, OKMindmap, Scratch, Facebook and methodological content and the application of STEM orientation in teaching and educational science research methods to apply for this study. 


\subsection{Experimental research}

The experimental style for this research based on the theories of Judith Bell, 1993, L.Cohen 2007.

\subsubsection{Designs in educational experimentation}

For this paper, we present one of the experiment taken with a group of 50 students in mathematics education major.

Step 1: WebQuest about WebQuest creation in OKMindmap style as in this page http://bit.ly/2gHErn7 was created and sent to Facebook class group as in figure 2 .

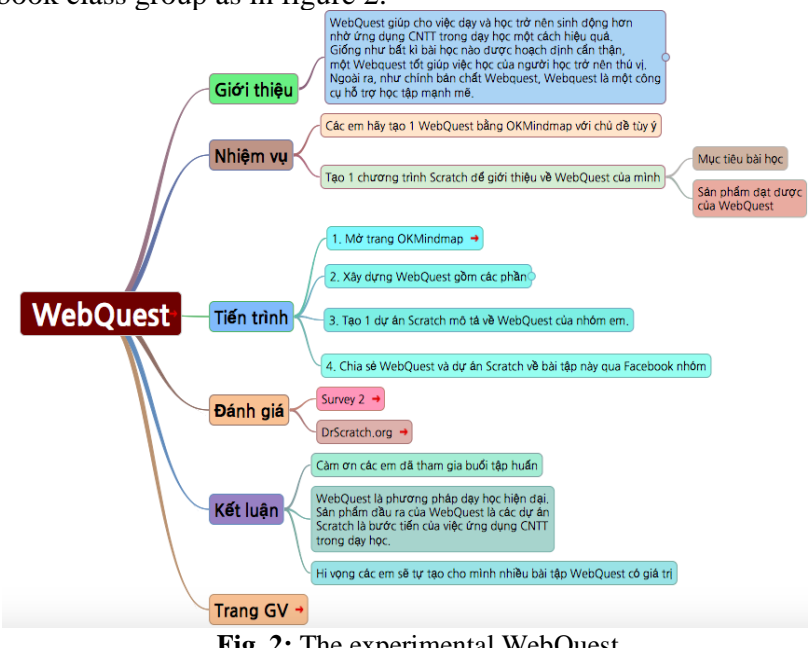

Fig. 2: The experimental WebQuest

Step 2: We created the link http://bit.ly/2xVdLcB collaborative working to brainstorm about real world problems and try to find out the solution for the problem. Figure 3 is the picture that student created collaboratively:

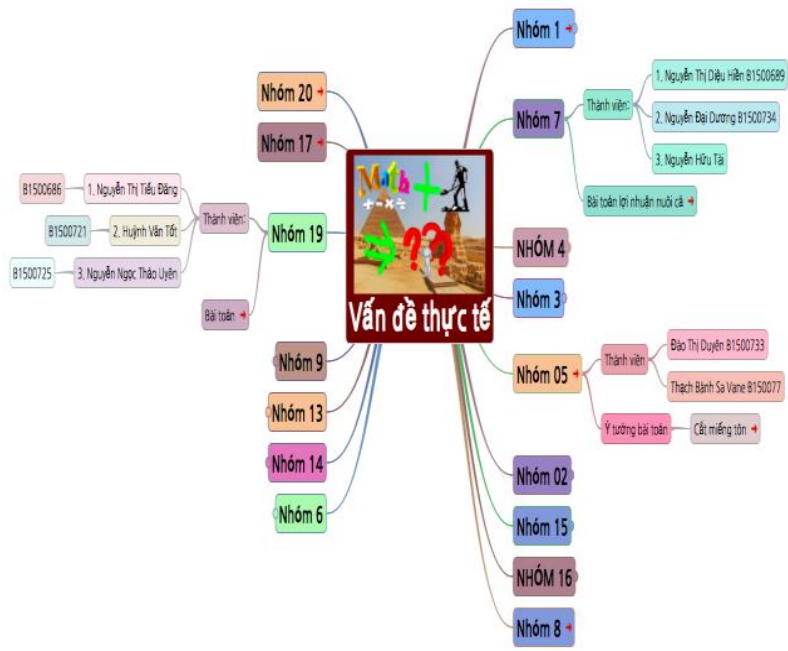

Fig. 3: Group working in OKMindmap style

Step 3: Students collaborate to work in problem solution and program with Scratch and add to the Studio: https://scratch.mit.edu/projects/175762264/ as in figure 4.

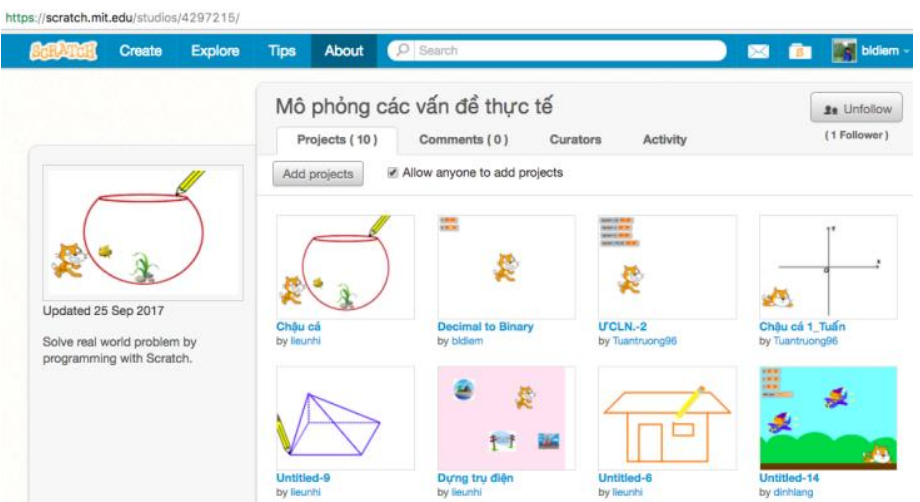

Fig 4: Scratch studion for simulation of real world problems

\subsubsection{Methods of data collection}

This educational experimentation collected data from:

- Observation studies:

- Questionaires

- Interviews:

\section{Results and discussion}

\subsection{How to apply this WebQuest model in STEM high- er education in Mekong Delta?}

Within two years of research, we trained more than 200 students in Can Tho University to create WebQuest with this model. The WebQuest library and Scratch Studios are shared public and attached hyperlinks in the the website http://webquest.ctu.edu.vn/ in figure 5 . We also announce that website in social network system as Facebook and Twitter to let teachers around Mekong Delta approach this new inquiry-based learning format.

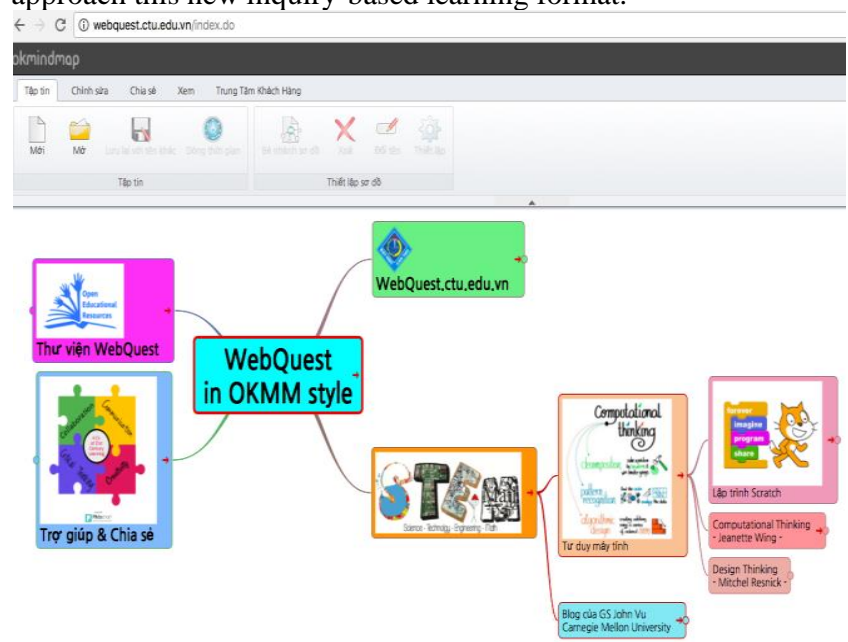

Fig. 5: The interface of CTU WebQuest portal http://webquest.ctu.edu.vn/

\subsection{How to evaluate the effect of this model?}

In order to evaluate the effect of the suggested model, we consider the WebQuest library and Scratch programs created by students. In the figure 6 , this is the webquest created by students in group 11 of the class of mathematics teaching method, course 41, School of education of Can Tho University. The problem was solved in kind of mindmap in figure 8 . Scratch project created by that group is https://scratch.mit.edu/projects/175762264/ and the evaluation by Dr. Scratch is as in figure 8 . 


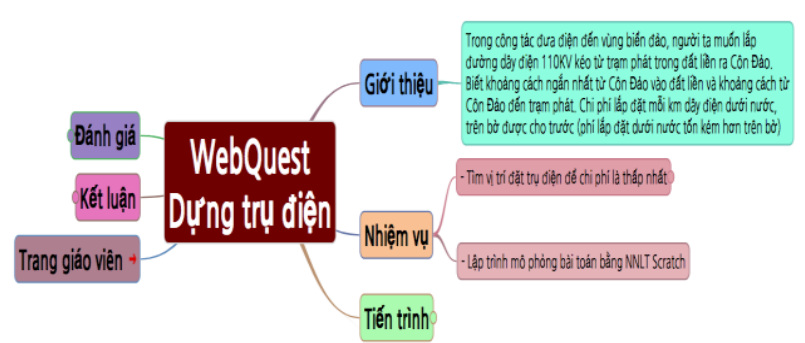

Fig. 6: WebQuest "Dựng trụ điện"

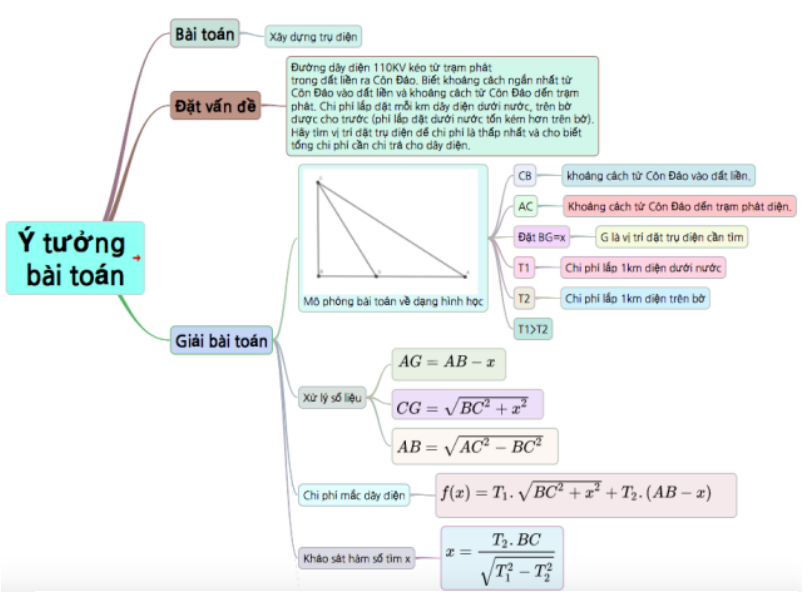

Fig.7: The problem idea created collaborating in OKMindmap style.

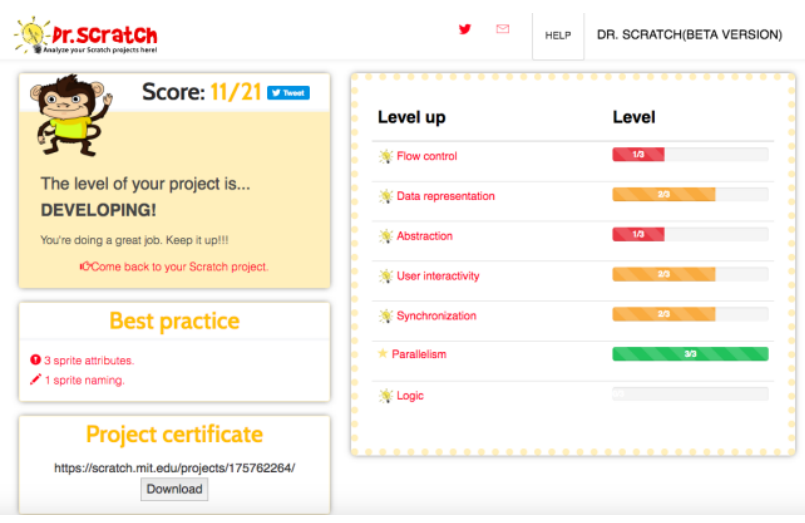

Fig. 8: The result of the project of group 11 assessed by Dr. Scratch

\subsection{Discussion}

The use of OKMindmap web 2.0 service for WebQuest platform as well as brainstorming in learning activities and Scratch programming for computational thinking practice in Task and Process steps is a new idea in WebQuest design. This helps teachers and students be able to work in a really creative learning environment. The online WebQuest library in OKMindmap style created by teachers and Scratch projects created by students in the assignment can be shared public online is a good OER for sharing and collaborating to quickly promote STEM education in Mekong Delta.

For further work, we are setting up a module to upgrade OKMindmap service so that the evaluation of WebQuest collaborating activities can be done automatically by Correspondence analysis (CA) [13] - an AI technique in computer science field - as well as making the system interface more user-friendly so that teachers and students can use our system as a convenient LMS in their teaching and learning activities. We may add Geogebra web service at https://www.geogebra.org/ to our model in order to help students learn mathematics more easily and use Geogebra productive projects for easily programming with Scratch.

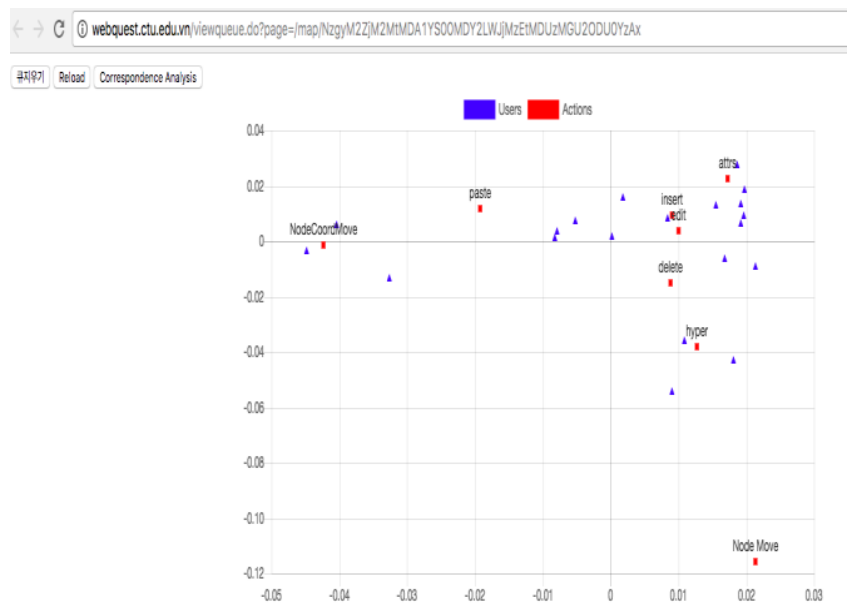

\section{Conclusion}

In this paper, we suggest a new WebQuest model for STEM education using web 2.0 services such as OKMindmap of Jinotech and Scratch of MIT. For this research activities, we have temporarily built the website http://webquest.ctu.edu.vn/, with idea to connect and share our works with teachers around Mekong Delta. This website could be a very useful channel in teacher professional development for this area.

OKMindmap and Scratch become more and more popular in our community. Teachers and student like to use the two tools for learning and teaching. It is very good effect to promote creative thinking skill as well as to broadcast the $21^{\text {st }}$ century thinking skills. The project based learning by Scratch programming is the first step to advance to STEM Robotics education. By several research experiments with students of Can Tho university, we believe that our research is valuable in STEM education for Mekong Delta development.

We hope to find some fund for permanently OKMindmap server setup and training activities in all schools in Mekong Delta to use our website as a LMS/OER for teaching and learning.

\section{Acknowledgement}

This research work is supported by Gyeongsang National University and Jinotech company in South Korea.

\section{References}

[1] E. Thompson, A. Luxton-Reilly, J. Whalley, M. Hu, and P. Robbins, "Bloom's Taxonomy for CS assessment," Tenth Australasian Computing Education Conference (ACE 2008), vol. 78. ACS, Wollongong, NSW, Australia, pp. 155-162, 2008.

[2] V. Thu Hằng, "Contruct the design process of hierarchy exercises in differentiated instruction by bloom's taxonomy," J. Sci. Educ. Sci., vol. 60, no. 6A, 2015.

[3] N. L. Webb, "Depth-of-knowledge levels for four content areas," Lang. Arts, 2002.

[4] K. Latuperissa, "Action Research on a WebQuest as an Instructional Tool for Writing Abstracts of Research Articles," Excell. High. Educ., vol. 3, no. 1, Aug. 2012.

[5] C.-S. Chang, T.-S. Chen, and W.-H. Hsu, "The study on integrating WebQuest with mobile learning for environmental education," Comput. \& Educ., vol. 57, no. 1, Aug. 2011.

[6] B. Dodge, "FOCUS: Five rules for writing a great WebQuest," Learn. Lead. with Technol., vol. 28, pp. 6-9-6-9, 2001.

[7] H. Won, "Innovative Collaborating Environment Building using OKMindmap Embedding Node Capability," Indian J. Sci. Technol., vol. 8, no. S9, May 2015.

[8] I. Vali, "The WebQuest Technique - How To Exploit New Technologies In Training Teachers," 2017, pp. 698-704.

[9] A. Hassanien, "Using Webquest to Support Learning with Technology in Higher Education," J. Hosp. Leis. Sport Tour., vol. 5, no. 1, 
May 2006.

[10] M. Resnick et al., "Scratch: programming for all," Commun. ACM, vol. 52, no. 11, Nov. 2009.

[11] J. M. Wing, "Computational thinking," Commun. ACM, vol. 49, no. 3, Mar. 2006.

[12] J. M. Wing, "Computational thinking and thinking about computing," Philos. Trans. Ser. Math. Phys. Eng. Sci., vol. 366, no. 1881, pp. 3717-3725, Oct. 2008.
[13] "The Essentials of Correspondence Analysis: A Simple Example," in Applied Correspondence Analysis, SAGE Publications, Inc., 1998, pp. 9-25.

[14] J. Bell, Doing Your Research Project, Buckingham UK: Open University Press, 1993.

[15] L.Cohen, Lawrence, K.Marrison, Research Method in Education, Routledge, Taylor\&Francis Group, London and New York, 2007. 